\title{
As ambiguidades do Iluminismo em algumas obras de Francisco de Goya: leitura de imagens
}

\author{
Camila Guidolin" \\ Francisco Fianco
}

\section{Resumo}

Pretende-se identificar as ambiguidades do pensamento e da obra de Goya através da análise de alguns de seus retratos de corte - Carlos IV (1789), La reina María Luisa con tontillo (1789) e La familia de Carlos IV (1800) - e da mais famosa de suas gravuras Capricho $n^{-} 43$, El sueño de la razón produce monstruos (1799). A tais ambiguidades relacionaremos as principais características do período histórico no qual viveu o artista, repleto de transformações sociais e culturais, para, através de uma análise reflexiva das imagens, compreender o quanto foi inovador o que Goya estava fazendo em termos de pintura ao mesmo tempo em que estava plenamente integrado à sociedade que suas vinculações intelectuais estavam criticando e transformando. Por fim, acompanharemos a crítica ao iluminismo nascente que já se faz entrever em suas gravuras, especialmente na já citada.

Palavras-chave: Goya. Iluminismo. Leitura de imagens.

* Graduação em Licenciatura Plena em História (2011) e mestrado em História na área de História Regional (2015) pela Universidade de Passo Fundo. Atualmente desenvolve o seu doutoramento em História no Instituto de Ciências Sociais da Universidade de Lisboa. Dedica-se a pesquisas sobre imaginário e representações no mundo islâmico, com ênfase em revoluções iranianas do século XX, nacionalismo iraniano, questões de gênero e homoafetividade no Oriente Médio. Recentemente vem desenvolvendo pesquisa sobre a arte e o pensamento oriental, com ênfase em análise das narrativas sequenciais e produções cinematográficas contemporâneas, além da relação entre as religiosidades e o mundo contemporâneo. E-mail: camilaguidolin@gmail.com

** Graduação em Licenciatura Plena em Filosofia (2002) pela Universidade do Vale do Rio dos Sinos, mestrado (2004) pela mesma instituição, e doutorado (2008) pela Universidade Federal de Minas Gerais. Tem experiência na área de Filosofia, com ênfase em Estética e Filosofia da Arte, tendo desenvolvido dissertação sobre Walter Benjamin (2004), sob orientação da Profa. Dra. Márcia Tiburi, e tese sobre Nietzsche e a Escola de Frankfurt (2008), sob orientação do Prof. Dr. Rodrigo Duarte. Atualmente é professor do Programa de Pós-Graduação em Letras e do Curso de Filosofia na área de Ética e Conhecimento, da Universidade de Passo Fundo. E-mail: fcofianco@upf.br

Data de submissão: 05/07/2017 - Data de aceite: ago. 2017 http://dx.doi.org/10.5335/rdes.v13i2.7181 


\section{Introdução}

O presente escrito tem como tema a ambiguidade presente nas obras do pintor espanhol Francisco de Goya, subjazendo aí a hipótese de que tais ambiguidades são oriundas do período de crises e transformações vivido pelo autor, a passagem do Antigo Regime para o Iluminismo. Nesse sentido, procederemos à análise de algumas obras desse pintor, a fim de verificar quais características do período podem se fazer presentes nos documentos imagéticos que serão alvo de nossa leitura.

Para tanto, dividiremos este texto em três partes: a primeira contextualizando Goya e o Iluminismo; a segunda analisando sua inserção social através de seus retratos de corte; e a terceira demonstrando o quanto esta inserção era apenas uma das facetas do pintor, que identificou, no movimento racionalista que estava vivendo e com o qual inclusive concordava, elementos perigosos e obscuros, o que se presentifica em sua obra através das gravuras, especialmente $\mathrm{O}$ Capricho $n^{\circ} 43$.

\section{Goya e o Esclarecimento}

Francisco de Goya y Lucientes (17461828) foi um dos mais impactantes e inovadores artistas de uma pátria nada tímida em termos de artistas inovadores e impactantes como a Espanha, tais como, para citar apenas a tradição que lhe é imediatamente precedente, Veláz- quez e El Greco. Pertencente temporalmente à geração de artistas que pintam sob a égide dos ideais revolucionários de França, como Jacques-Louis David, para citar o mais famoso deles, Goya, paradoxalmente, não pode ser tranquilamente ajustado aos modelos artísticos, sociais e culturais de seu tempo, ao mesmo tempo se adequando a eles e ultrapassando-os. Embora seus retratos, a qualidade técnica que demonstra neles, desenvolvimento consequente de sua instrução em Roma e seu estudo dos mestres italianos, entre os quais se nota a influência da luminosidade de Tiepolo, que terminou seus dias em Madrid, e a perícia na representação da seda e do ouro de Ticiano, Goya não era, nestes retratos, um mero cortesão subserviente, pois retratava seus soberanos implacavelmente.

Fazia com que seus traços revelassem toda a sua vaidade e feiura, ganância e empáfia. Nenhum pintor de corte, antes ou depois, deixou jamais tal registro de seus patrocinadores (GOMBRICH, 2013, p. 371).

Mas talvez mais eloquente ainda do que seus retratos de corte, uma das facetas deste artista multifacetado, seja sua produção de gravuras, especialmente seus temas perturbadores. Diferentemente de outros gravuristas eminentes, como Albrecht Dürer ou Rembrant, Goya não usava narrativas bíblicas como tema, mas a crítica caricatural dos vícios que percebia no seio de sua própria sociedade ou mesmo, em um movimento de interiorização ainda mais íntimo, os terrores de seus próprios pesadelos. Isso inaugura uma maneira inovadora 
de abordar a composição imagética. Alguns destes devaneios podem ter como inspiração longínqua os homúnculos de Bosch, que Goya pode ter tido a oportunidade de ver no Prado, porém sempre estas influências vão transtornadas pela sua própria genialidade. "Bosch introduz os homens em seu universo infernal, Goya introduz o infernal no universo dos homens" (MALRAUX, 1950, p. 110 apud TODOROV, 2014, p. 70).

Até Goya, o artista obedecia aos cânones definidos em termos de representação fiel da realidade. A ruptura que ele causa, intencional e conscientemente, possibilita tanto que os poderosos sejam representados com a rigorosidade que merecem quanto que 0 artista se expresse pessoalmente através da imagem, compondo poeticamente os temas a partir de sua percepção subjetiva de mundo. Era, talvez, o início da art engagé que só veremos cerca de dois séculos mais tarde.

Com efeito, esta foi a consequência mais evidente da quebra da tradição: os artistas sentiram-se livres para passar para o papel suas visões particulares, como até então apenas os poetas haviam feito (GOMBRICH, 2013, p. 371).

Isso nos permite abordar o corpus imagético deixado por Goya não apenas do ponto de vista da arte, como igualmente a expressão de um sistema de pensamento, quer o seu autor estivesse ou não ciente dessa dimensão de sua obra. O que não quer dizer, absolutamente, que Goya tenha provocado uma radical mudança de paradigma em arte logo, durante e após a sua obra, mas que, olhando retrospectivamente, podemos perceber em suas imagens o testemunho de uma mudança muito maior do que algo que ocorra apenas dentro do âmbito das artes: uma transformação social e cultural em diversos aspectos, que se ilustra pela arte, assim como através de outras modalidades de ação humana.

Claro que, ao dizermos que Goya pode ser encarado como um pensador, não estamos sugerindo que ele tenha, através de suas obras, elaborado um conjunto sistemático e consciente de análise filosófica e social, se não que, enquanto observadores de sua obra, sejamos nós que podemos tentar ordenar aquilo que aparece nelas enquanto um "pensamento figural", para usar o termo que Todorov toma emprestado a um ensaio sobre Goya de Yves Bonnefoy. E tal manifestação se desenvolve em uma área intermediária entre os extremos da mera representação imagética e o da análise teórica distanciada, de maneira que ele venha a englobar todo o conjunto de representações de uma época, seu horizonte simbólico, seu conjunto imaginário. Na medida em que o iluminismo seja não apenas uma época histórica delimitada e distanciada pelas brumas dos séculos, mas também, de diversas formas, o alicerce sobre o qual repousam as nossas hodiernas estruturas sociais, econômica, culturais e mesmo psicológicas, podemos justificar o interesse por este pintor e gravurista em especial.

Portanto, nosso foco dar-se-á primeiramente no sentido de compreender 
de que maneira ele pode impactar a tradição artística de sua época e abrir as perspectivas para aquilo que as artes visuais vieram a se transformar no futuro. Em um segundo aspecto, pretendemos entender de que maneira o pensamento iluminista e as transformações socioculturais pelas quais passou Goya estão imbricadas em sua obra ou, de outra forma, de que maneira sua obra condicionou toda uma maneira de representar estas transformações para a posteridade, tornando-se indissociáveis do assunto que representam.

Para o desenvolvimento desta análise, selecionamos alguns dos retratos executados por Goya enquanto pintor de câmara. O Goya dos retratos régios e da sociedade madrilena das últimas décadas do século XVII e primórdios do século XIX deixa verter-se em uma perspectiva dúbia, afinal, o artista é, nesse contexto, não apenas o observador privilegiado, aquele que é convidado para retratar - através da dinâmica da representação ensaiada - a corte, mas também aquele que se projeta para o que há fora do espaço régio e consegue com isso captar uma sociedade em profunda transformação. Optamos por observar apenas dois dos primeiros retratos de divulgação da imagem dos novos monarcas, logo após Carlos IV subir ao trono de Espanha em 1789, intitulados Carlos IV e La reina María Luisa con tontillo. Além dos retratos individuais dos monarcas, selecionamos também a obra La familia de Carlos IV, de 1800, e
- Capricho $n^{\circ} 43$, El sueño de la razón produce monstruos, de 1799. O Capricho $n^{\circ} 43$, embora aparentemente desconexo do conjunto de retratos destinados a representar a imagem da monarquia e da nobreza espanhola de finais do século, deixa transparecer o sentido mais complexo e emblemático que a obra de Goya nos revela - tanto nas suas contradições internas como nas do período que ele presencia. O nosso propósito é não o de realizar uma leitura exaustiva desses retratos, mas o de evidenciar alguns elementos que consideramos significativos para a estruturação da análise pretendida e que, de alguma maneira, estabeleçam um diálogo com as outras facetas de Goya e também com as transformações em curso nesse período.

Quanto ao primeiro aspecto, temos já algumas indicações formuladas pelo próprio Goya em seu relatório sobre a pesquisa em artes visuais enviado à Academia de San Fernando em Madrid, em outubro de 1792:

Não há regras em pintura, e a opressão, ou a obrigação servil de fazer estudar a mesma coisa, ou de seguir o mesmo caminho, é um grande obstáculo para os jovens que escolhem esta arte tão difícil, que se aproxima do divino mais do que qualquer outra, por representar tudo o que Deus criou (GOYA, 1981 apud TODOROV, 2014, p. 30).

Ao pregar a liberdade de seus alunos, em uma clara afronta à tradição, Goya define a arte como dotada de seus próprios pressupostos, de maneira que ela mesma, em um exercício iluminista de liberdade e autonomia, seja julgada por 
seus méritos segundo critérios próprios. Todorov destaca (2014, p. 32) três ideias principais destes manifesto de Goya pela pintura revolucionária: a de que a arte não deve ser imitação passiva da realidade; a de que a arte deve se direcionar mais à comunicação de ideias do que de formas agradáveis; e de que os artistas, independentemente do seu nível, não podem ser compelidos pelas regras artificias, pois, absolutamente, não há regras na pintura em termos de forma e método, de maneira que o único parâmetro da arte seria o de revelar o mundo.

E tal possibilidade, a de que um sujeito se expresse de forma autônoma e livre, em um rompimento radical com a tradição, seja ele artista ou meramente um cidadão, corresponde a uma transformação na sensibilidade e no pensamento, com consequências políticas e econômicas na história, que temporalmente costumamos localizar na passagem do século XVIII para o XIX, exatamente, como vimos acima, o período de vivência de Goya. Na filosofia, por tradição de tradução da língua alemã (Aufklärung), costuma-se chamar este movimento de Esclarecimento. Em outras áreas do conhecimento, especialmente no desenvolvimento do pensamento empirista inglês (Enlightment) e na história, por um galicismo mais do que justificado, passou-se a conhecer este conjunto revolucionário de Iluminismo (Philosophie des lumières) (ABAGNANO, 1981, p. 509). Esse novo modelo de pensamento se alimentava da capacidade crítica da razão humana para corrigir e reorganizar a existência humana em todos os seus aspectos, tanto individuais, cognitivos, estéticos, éticos, quanto coletivos, sociedade, economia, política.

Ao possibilitar a síntese, aparentemente irreconciliável até então, entre racionalismo e empirismo, o alemão Immanuel Kant pode ser considerado o mais denso representante do esclarecimento como movimento intelectual. Sua extensa obra não apenas postula a racionalidade como instrumento privilegiado de crítica do mundo como inclusive, o que de certa forma veio a ser uma intenção malograda, pressupunha que tal racionalidade seria capaz de estabelecer seus próprios limites. Nesse sentido, a maior contribuição do Iluminismo é a possibilidade de, munido da racionalidade crítica, assaltar a tradição como mecanismo de fundamentação dos ritos sociais e suas estruturas de organização, como já vimos manifesta tanto na concepção estética de Goya quanto na crítica social que ele faz através de suas gravuras, conforme veremos mais adiante.

E esse exercício crítico não se faz meramente no âmbito das ideias, na esfera intelectual. A capacidade crítica racional deve estar a serviço da humanidade como bem maior e finalidade última das ações, sendo o esclarecimento um movimento de luta pela libertação dos indivíduos da opressão sedimentada pela tradição e pela superstição. Para que isso aconteça, é necessário que tomemos a liberdade como indissociável 
da autonomia e da responsabilidade, a tríade com a qual simultaneamente nos onera e lisonjeia a racionalidade crítica. Nas célebres palavras de Kant, ao responder à pergunta sobre o que seria $o$ Esclarecimento, em 1783:

\begin{abstract}
Esclarecimento [Aufklärung] significa a saída do homem de sua menoridade, pela qual ele próprio é responsável. A menoridade é a incapacidade de se servir de seu próprio entendimento sem a tutela de um outro. É a si próprio que se deve atribuir essa menoridade, uma vez que ela não resulta da falta de entendimento, mas da falta de resolução e de coragem necessárias para utilizar seu entendimento sem a tutela de outro. Sapere aude! Tenha a coragem de te servir de teu próprio entendimento, tal é portanto a divisa do Esclarecimento (KANT, 1783, p. 1, grifo do autor).
\end{abstract}

Porém tal independência da humanidade mediada pela razão não se deu exatamente da forma como fora planejada, aquilo que Goya percebeu de forma talvez inconsciente e que foi tematizado pelos críticos do esclarecimento no século XX. Os desvios do pensamento iluminista são poderes muito bem ilustrados pelo primeiro trecho do capítulo dedicado ao conceito de esclarecimento no mais eminente texto sobre o assunto, Dialética do Esclarecimento, de Theodor W. Adorno e Max Horkheimer, publicado em 1944, período no qual o racionalismo iluminista estava em seu auge enquanto método de solução lógica de problemas nos campos de concentração e exterminado, racional e cientificamente projetados para serem mais eficientemente fábricas de matar. $O$ trecho que abre a obra é o seguinte:
No sentido mais amplo do progresso do pensamento, o esclarecimento tem perseguido sempre o objetivo de livrar os homens do medo e de investi-los na posição de senhores. Mas a terra totalmente esclarecida resplandece sob o signo de uma calamidade triunfal. O programa do esclarecimento era o desencantamento do mundo. Sua meta era dissolver os mitos e substituir a imaginação pelo saber (ADORNO; HORKHEIMER, 2006, p. 17).

$\mathrm{E}$ tal desencantamento se percebe, como veremos adiante, em diversas gravuras de Goya, ao tecerem a crítica às superstições e às crendices populares, bem como às tradições que estas sustentam, em prol de uma visão mais livre e secular da realidade. $\mathrm{O}$ desenvolvimento do texto frankfurtiano chama a atenção, porém, para o fato de que há algo de patriarcal e dominador neste processo de desencantamento, de perigoso e potencialmente violento. Isso se ilustrará, mais adiante, em outra série de gravuras, sobre os desastres da guerra, pois é justamente a razão, a convicção da verdade, que permite a invasão, a pilhagem, a eliminação do diferente, a libertação forçada. $\mathrm{O}$ grande interesse da humanidade no conhecimento é a possibilidade de uso deste na dominação do mundo, dos outros homens e de si mesmo. Seguindo este raciocínio, o mundo desencantado não conserva mais nenhum mistério a ser desvelado, tampouco o desejo de desvelamento de áreas incógnitas, se não a plena dominação do já existente. A substituição do pensamento mítico pelo pensamento científico ocasiona o desencantamento do mundo, de maneira que 
os objetos não tenham mais alma, não tenham mais particularidade. O próximo passo é a transformação dos homens em objetos, sua planificação.

Não é mera coincidência que o surgimento do esclarecimento coincida historicamente com o surgimento do sistema capitalista e com os movimentos de massa. Assim sendo, a identificação do sujeito individual com os mecanismos ideológicos de um grupo, motor dos movimentos de massa, ajuda a explicar o sucesso do iluminismo e sua expansão pela Europa e mesmo pelo mundo primeiro como um rastro de pólvora revolucionário e, logo em seguida, pela invasão bem-intencionada dos territórios europeus pelo exército libertador napoleônico. Parece, ao fim e ao cabo, que o esclarecimento serviu neste determinado momento histórico como a justificativa ideológica da dominação e da invasão, assim como serviram, em outros momentos outras diversas ótimas ideias da humanidade, desvirtuadas e deturpadas, para justificar a projeção no mundo, daquilo que os lideres trazem de sórdido dentro de si e têm a capacidade de fazer ecoar nas gentes.

Porém, o aspecto mais intrigante do esclarecimento a ecoar naquela que talvez seja a mais intrigante gravura de Goya, El sueño de la razón produce monstruos, pode ser considerado a relação do pensamento científico e sua tentativa de substituição do pensamento mítico. Esse esclarecimento que vem substituir a superstição é ele mesmo um tipo de mitologia, com todas as características de um argumento mitológico ou religioso, como a capacidade de repetição infinita ou a autoridade inquestionável de seu discurso. Porém, ao contrário do pensamento mítico, que sempre se caracterizou por ser pluralista e agregador, o pensamento desencantado é violento, planificador e suporta apenas uma única forma de expressão da verdade, de modo a banir, eliminar ou absorver qualquer pensamento dissidente.

Não nos parece, portanto, indiferente ou casual que na obra de Goya, em meio a uma crítica esclarecida das superstições e ao registro das consequências nefastas que podem se originar no pensamento esclarecido e libertador, apareça a figura do demônio, do grande bode negro, do Aquelarre. Ele talvez seja a última instância, obscura e ameaçadora, é verdade, de resistência ao processo totalizante e avassalador do desencantamento do real.

\section{Pintor e cortesão}

A vida de Francisco de Goya y Lucientes foi marcada pelos eventos que também redefiniram o cenário europeu no final do século XVIII e princípios do XIX. A sua trajetória particular percorrerá desde as estruturas do antigo regime e a experiência do barroco tardio de inspiração italiana até a afirmação do romantismo, uma das expressões da idade moderna. A evolução social e cultural concebida nesse período, no entanto, foi 
não somente um reflexo do desgaste da antiga ordem social, mas também um resultado dos processos instalados a partir de uma nova dinâmica construída no âmbito das transformações culturais, sociais e políticas do período e motivada, em alguma medida, pelo pensamento ilustrado. Ao percebermos a Ilustração não enquanto uma doutrina fechada, mas como um movimento intelectual dinâmico e heterogéneo, podemos entender algumas das formas pelas quais ela se manifestou em Espanha e, sobretudo, na obra de Goya. É no contexto das crises do antigo regime que percebemos a relação dos movimentos concebidos sob a interferência das ideias ilustradas com o deteriorar do modelo clássico de Corte e do alcance do seu poder e influência na sociedade espanhola.

Agora pertencente ao meio dos "esclarecidos”, nem por isso Goya procura expressar suas novas ideias através da pintura. [...] Ele parece haver atingido o seu objetivo, o êxito social, e, embora seja melhor do que seus colegas, nada indica ainda que, nos anos vindouros, revolucionará a pintura europeia, ao mesmo tempo que o pensamento das Luzes! (TODOROV, 2014, p. 29).

No ano de 1789, Goya será nomeado pintor de câmara do rei e, dez anos depois, primeiro pintor de câmara do rei e tornar-se-á o artista mais utilizado pelo casal real. No entanto, enquanto testemunha de uma revolução em curso, virá a ser também o artista arquetípico do seu tempo. Através da sua obra, vemos o retrato do triunfo e do tormento, dos panos nobres e dos corpos desmembrados, das majas desnudas e das bruxas voadoras, das insígnias reais e dos horrores da guerra. Goya foi

[...] sacudido y dividido por las contradictorias demandas de sus mecenas, por la lealtad a la elite española y al pueblo y por la destrucción de las anteriormente seguras divisiones entre arte público y deseos privados (EISENMAN, 2001, p. 82).

A linha que divide esses lados aparentemente tão antagônicos nunca foi completamente clara em sua arte que, por muitas vezes, fê-los colidir e sobrepor-se.

A primeira imagem que apresentamos corresponde a um retrato de corpo inteiro do rei Carlos IV. Filho de Carlos III e de María Josefa Amalia de Sajonia, nasceu em Portici, em 12 de novembro de 1748, e casou com María Luisa de Parma em 04 de setembro de 1765. Carlos IV tornou-se rei nas vésperas da Revolução Francesa, em 1788, época de conflitos internacionais e de divisões sociais profundas. 
Figura 1-Carlos IV

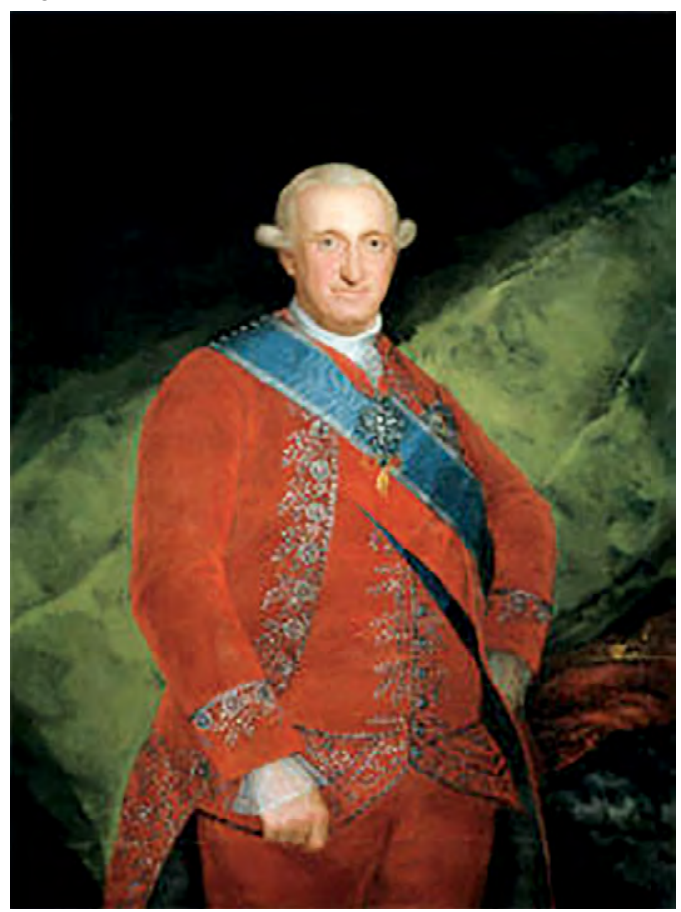

Fonte: Goya (1789).

Na tela, Carlos IV (1748-1819) é representado com um traje de seda granada, bordado com fios de prata, e detém na mão direita o bastão de mando de capitão geral a substituir a antiga bengala por las ordenanzas militares, de Felipe V, de 1706. A sua veste ostenta todas as suas condecorações: a grande cruz e banda da ordem de Carlos III, a napolitana de San Jenaro e a francesa de Saint Esprit. Ao seu lado descansa sobre um manto cor púrpura forrado de arminho a coroa real, símbolo da realeza. $\mathrm{O}$ retrato de Carlos IV encontra uniformidade como o de La reina María Luisa con tontillo, pintados ambos por Goya na ocasião da sua ascensão ao trono.
Figura 2 - La reina María Luisa con tontillo

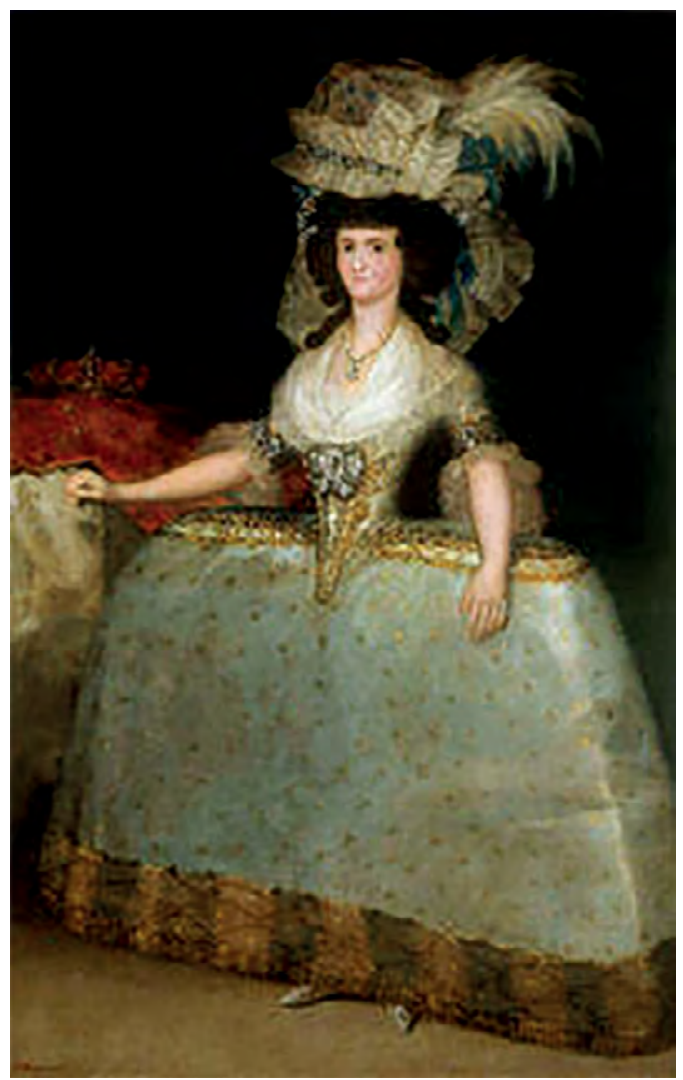

Fonte: Goya (1789).

María Luisa de Parma (1751-1819), sua prima, tornou-se sua esposa aos 14 anos e assumiu, depois de rainha, um lugar importante na política espanhola. No seu retrato, a rainha veste um tontillo (armação interna para saias) com volume lateral e saia achata atrás e na frente. $\mathrm{O}$ traje remonta à moda feminina da nobreza do século XVII, elemento do vestuário real que entrará em desuso após a revolução francesa. Na cabeça, veste uma escofieta (toucado preparado com adornos variados) de 
fitas, penas e ornamentos de diamante. María Luisa ostenta a ordem das Damas da Cruz Estrelada, concedida pela imperatriz María Teresa de Áustria para as senhoras da realeza espanhola, e usa também um colar de diamantes. Os elementos do seu vestuário deixam transparecer a influência francesa presente na cultura espanhola em vários aspectos. Goya confere aos dois retratos a opulência digna da corte através dos tecidos reais e das inúmeras insígnias, além do realce alcançado pelo brilho das joias. Os destaques em branco e amarelo com toques furtivos fazem-nos lembrar da liberdade dos pincéis de Velásquez, pintor que Goya apreciava e cujas obras serviram como inspiração em muitos dos seus retratos régios. A grandiosidade das cenas, no entanto, não encontra paridade com as suas feições. No rosto de Carlos IV, descobrimos um rei comum cuja expressividade não parece condizer com o que se espera de uma face real. María Luisa, com um certo ar de desdém, parece espreitar algum movimento que se desenrola ao lado do artista. Em um momento de ruptura entre a representação pública e os aspectos da vida privada, o olhar da rainha leva-nos inconscientemente a pensar no ambiente que a rodeia, no espaço que existe além da encenação. O caráter comemorativo desses retratos dissimula com a emoção banal que a sinceridade dos pincéis de Goya encontra, formando um conjunto de elementos interpretativos que surgiriam de forma mais explícita e intensa nas suas gravuras.
Entre os trabalhos mais importantes realizados por Goya enquanto primeiro pintor de câmara do rei, encontra-se o retrato La familia de Carlos IV. O quadro foi realizado entre Aranjuez e Madrid, na primavera e no verão de 1800 , pouco tempo depois de Goya pintar La maja desnuda. Nele aparecem retratados, da esquerda para a direita, os seguintes personagens: Carlos María Isidro (1788-1855), filho de Carlos IV e María Luisa de Parma e segundo na sucessão ao trono; o Príncipe de Astúrias, futuro Fernando VII (1784-1833); Goya, o próprio artista a pintar, assim como o fez Velásquez em Las meninas; a infanta María Josefa (1744-1801), irmã do rei; ao lado, uma jovem desconhecida que poderia estar a representar a futura esposa de Fernando, visto que aparece com a cabeça virada; María Isabel (17891848), filha menor dos reis; ocupando o centro da tela a rainha María Luisa de Parma (1751-1818); Francisco de Paula (1794-1865) de mãos dadas a sua mãe; o rei Carlos IV (1748-1819), em posição avançada em comparação ao grupo e com as costas viradas para o seu irmão; no grupo da direita, situam-se Antonio Pascual (1755-1817), irmão do monarca, e Carlota Joaquina (1775-1830), rainha de Portugal e filha mais velha dos reis; encerram o grupo o príncipe Luis de Bourbon (1799-1883), futuro rei de Etruria, e a sua esposa María Luisa (1782-1824), que segura nos braços o seu filho Carlos Luis. 
Figura 3 - La familia de Carlos IV

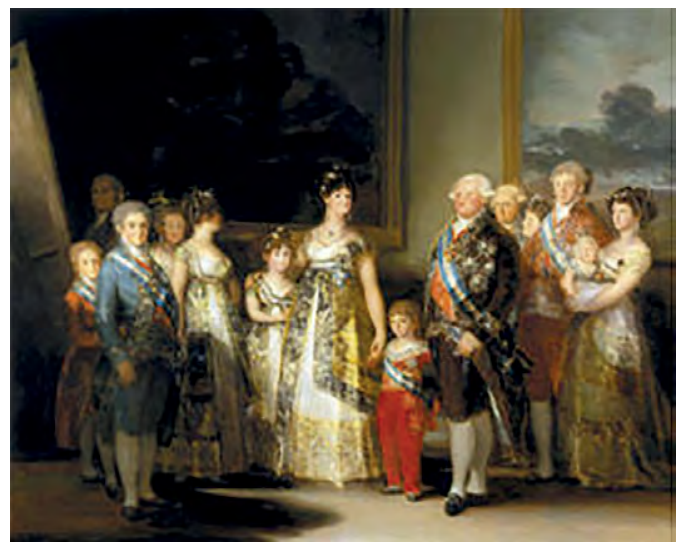

Fonte: Goya (1800).

Todos os homens retratados ostentam a Ordem de Carlos III, enquanto as mulheres vestem a moda do Império e levam a banda da Ordem de María Luisa. O rei Carlos IV também porta a insígnia das Ordens Militares e da Ordem de Cristo de Portugal. Os retratos de família assinalam a importância da divulgação da imagem do soberano e também do conjunto familiar, evidenciando o elemento dinástico de continuidade típico do sistema monárquico e tão caro para o fortalecimento da imagem da realeza. $\mathrm{O}$ "retrato de todos juntos", como era chamado pela rainha María Luisa, perde em rigor e protocolo ao representar uma rainha maternal, que envolve em carinhos seus filhos mais novos. Os bastidores são visíveis, através deles deixa-se ver representado na tela o próprio artista, ponto de ruptura com a representação ensaiada, propõe uma quebra no aspecto "oficial" da cena. O quadro, visivelmente influenciado pela tela Las meninas, de
Velasquez, é de grande complexidade e sofisticação. Cada um dos personagens tem o olhar apontando para uma direção, e parecem pegos de surpresa, como se o retrato em óleo sobre tela tratasse no fundo de uma fotografia. Embora o rei Carlos IV e o seu sucessor, futuro Fernando VII, estejam posicionados a frente do grupo, é a imagem da rainha María Luisa que se sobrepõe aos demais elementos da tela. Em termos de composição artística, podemos perceber nesse retrato a maestria de Goya. O artista opta por romper a simetria aparente da tela ao tornar o centro da imagem a figura de Francisco de Paula. A centralidade que os tons em vermelho dos trajes do infante cria remete-nos às composições renascentistas inspiradas na proporção áurea.

Esse retrato de família, especialmente lembrado pela sua "modernidade", revela a marca do artista não apenas no alcance técnico da sua realização, mas também nos aspectos pessoais - fruto das transformações que o próprio artista vivia - que Goya oferece à tela. Essa imagem da monarquia espanhola perde qualquer caráter divino. Os traços psicológicos dos personagens são visíveis, e a sua humanidade sobrepõe-se através da exibição não caricatural que cada rosto revela entre a feiura, a surpresa e o desconforto. As pequenas deformações que surgem no retrato de família estão ligadas aos aspectos de mutação que a sociedade do período vivenciava. 
De forma casi imperceptible, al final del siglo XVIII, es decir, en la última fase de la Ilustración, se han transformado las concepciones éticas de los españoles, quizá también porque la presencia de la literatura extranjera es más intensa y los discursos en torno a la moralidad son influidos por los que circulan en el resto de Europa (SÁNCHEZ-BLANCO, 2007, p. 290).

O cenário de fundo para a inspiração de Goya não se restringe ao âmbito da Espanha. O ambiente cultural das elites nas quais ele se insere é permeado pelas reverberações do pensamento iluminista oriundas de França que, ainda que lentamentes, se estabelecem com solidez ao longo de todo o século XVIII, abalando a credibilidade da tradição e ampliando os espaços de crítica social.

Através de uma notável elaboração histórica e uma aplicação das teorias sociológicas, Norbert Elias concebe o estudo intitulado $A$ Sociedade de Corte. Nesse livro, o autor propõe analisar a corte de Luís XIV, o Rei-Sol, e sua elaborada estrutura social alicerçada sobre símbolos de status e prestígio, tais como arquitetura e etiqueta. A partir da análise das figurações, o autor estuda não um rei ou uma corte em particular, mas as relações sociais e suas interdependências. Nesse sentido,

[...] os indivíduos são apresentados da maneira como podem ser observados: como sistemas próprios, abertos, orientados para a reciprocidade, ligados por interdependências dos mais diversos tipos e que formam entre si figurações específicas, em virtude de suas interdependências (ELIAS, 2001, p. 51).
Partindo dessa concepção particular para olhar e perceber o papel do indivíduo e das suas relações e tendo como base teórica a perspectiva sociológica, Elias reconhece as propriedades estruturais próprias da sociedade de corte. Em virtude dessa rede específica de interdependências, o autor irá problematizar a partir do que ele considera ser a questão fundamental para a análise da sociedade de corte: o que torna possível que milhares de pessoas se deixem governar repetidamente durante séculos por uma única família ou por seus representantes? E, como complemento a essa provocação: por que essa posição social do monarca "absoluto" encontra-se em vias de desaparecer? O caso específico da monarquia espanhola ao fim do século XVIII é sintomático das provocações que o autor lança já para o caso da corte francesa de Luís XIV. No entanto, todo o contexto conturbado e atravessado pelas transformações profundas, que podemos acima apresentar de forma mais específica para o caso da Espanha, torna o nosso caso um exemplo único de análise da corte real no Antigo Regime. Isso se deve, sobretudo, ao momento histórico e ao modelo particular da monarquia espanhola nesse contexto. Por isso não podemos aplicar a mesma análise que Norbert Elias dedicou ao caso francês, nem mesmo identificar para esse contexto uma organização social como a da sociedade de corte.

Na obra de Goya, a corte, espaço ilustrativo de uma vida coletiva ritualizada, 
é questionada. O seu papel enquanto sociedade particular que busca definir as relações e as interdependências entre os indivíduos a partir do símbolo, do rito e da etiqueta já apresenta um desgaste irreversível. A reverberação desse sintoma através da obra de Goya fica latente não somente nos retratos régios executados em torno da família do rei Carlos IV, mas também em obras transversais, com motivações menos cortesãs e, quiçá, mais interessadas em representar outros aspectos da sociedade espanhola desse período.

En el final de una época de luces y de sombras, de modernidad y de tradición, de riqueza y de miseria, de reformas que no habían cambiado los fundamentos tradicionales de la monarquía y de nuevos aires para la contrarreforma religiosa, los Caprichos de Goya indican bastante más que una profunda crisis psíquica y de conciencia sufrida por el artista en 1792 (TORRES, 2008, p. 623, grifo do autor).

A representação particular de cada personagem, a sensibilidade histórica que o artista imprime na tela e a sinceridade subjetiva, transposta para o traço e para o pincel, são o resultado de um conjunto de mudanças observáveis a um nível global - se pensarmos as transformações em curso nesse período - e também pessoal - tendo em conta a captação desses fenómenos e a interiorização dessas mudanças pelo próprio artista. Um detalhe importante a perceber é a cronologia dos seus trabalhos. $\mathrm{O}$ Capricho $n^{\circ} 43$ é realizado poucos anos antes do retrato La familia de Carlos $I V$. O Goya dos retratos régios revelado no segundo trabalho é inevitavelmente o Goya que se debate entre os sonhos da razão na primeiro.

\section{Artista e crítico social}

Apesar de estar ligado praticamente desde o início de sua carreira artística às altas esferas da sociedade espanhola, Goya, como diversos intelectuais de seu tempo, compartilhava do interesse por festividades e atividades das classes mais populares e camponesa, o que se exemplifica pelas diversas cenas de colheita, profissões humildes, ou mesmo de moços e moças trajados com a simplicidade dos plebeus, os majos e as majas. Esse interesse pelo povo, pela simplicidade e pelos trabalhos mais humildes é desenvolvido em arte dentro, obviamente, de um ambiente intelectual iluminista e revolucionário, ainda que tal valorização se de por parte das camadas mais abastadas da sociedade e que tenha entre os nobres, ainda que paradoxalmente, alguns de seus entusiastas. Exemplos dessa esquizofrenia político-ideológica abundam, e mesmo Goya pode ser entendido como um iluminista sem necessariamente ser um republicano ou um antimonarquista:

Bem integrado a esse novo ambiente, Goya adota certas maneiras dele, de modo que acrescenta um "de" ao sobrenome e assina cartas ao amigo como "teu Francisco de Goya" (TODOROV, 2014, p. 23).

$\mathrm{O}$ ambiente cultural das elites nas quais ele se insere é permeado por ideias iluministas oriundas de França que, ain- 
da que lentamente, se estabelecem com solidez ao longo de todo o século XVIII, abalando a credibilidade da tradição e ampliando os espaços de crítica social. Isso não significa dizer que o esclarecimento espanhol tenha sido um estudo sistemático de determinado pensador ou de determinada doutrina, sendo uma amálgama amorfa e anônima de sentenças e pensamentos popularizados a partir da massificação e consequente superficialização do pensamento iluminista. Como base quase comum a todas estas variações possíveis de desenvolvimento intelectual podemos colocar a crítica da tradição e da autoridade em termos de conhecimento, com uma consequente desqualificação da autoridade da Bíblia e de qualquer texto que se possa considerar sagrado ou que tenha na antiguidade seu argumento de autoridade, bem como das superstições, crendices populares, medos sociais. Em detrimento da tradição, valoriza-se a busca da verdade através do esforço individual e de métodos racionais e empíricos, tanto na perseguição da verdade quanto na construção do conhecimento, principalmente, na administração racional das coisas públicas e na gestão das coisas de estado.

Isso abre em Espanha o espaço para um campo de batalha entre esta elite intelectualizada e progressista e um grupo alijado do poder, mais próximo da sensibilidade popular, apegado às velhas tradições, à autoridade do clero, ao que na obra de Goya vai figurar como obscurantismo, talvez até mesmo como uma tentativa de se livrar das suas origens humildes e abraçar este novo estilo de vida que o sucesso como pintor lhe proporciona. A grande guinada, que vai transformar um pintor talentoso em um gênio da pintura, se dá a partir de 1792, ano em que sua estadia na Andaluzia corresponde ao seu adoecimento misterioso seguido de, entre outros diversos sintomas, enxaquecas e progressiva perda auditiva, quebrando um fluxo contínuo de ascensão social que poderia ter ocasionado em Goya um certo conformismo intelectual.

Tal intuição é corroborada por uma nota de Javier Goya, filho do pintor, que logo após a morte do pai declara que este havia estudado Velázquez e Rembrandt, observado a natureza e, acima de tudo, aprendido a olhar o mundo com outros olhos a partir de sua própria surdez. No ano seguinte a essa nefasta estadia andaluz, outro evento pode ter chocado sua sensibilidade de artista, embora tenha acontecido no mais público dos palcos, a política internacional europeia, ao contrário do acontecimento privado de seu adoecimento: em 1793, mais precisamente no mês de janeiro, é guilhotinado em França o rei Luís XVI por seus próprios súditos, revelando uma ordem social frágil e em vias de profundas transformações. Essa mudança de perspectiva se faz notar em sua obra, pois logo ele começa a pintar obras que não haviam sido encomendadas, ou seja, que obedecem apenas a uma necessidade interna de expressão, ao que nós pode- 
ríamos chamar um "capricho" do pintor, para brincar com o sentido hodierno da palavra, diferentemente de seu contexto, no qual significava uma fantasia, uma invenção. É neste momento que surgem obras como, por exemplo, a série das Tauromaquias. O que se destaca nas obras deste período é uma certa crueza, uma certa incompletude, o que demonstra o quanto, para Goya, a arte vale a sua intenção, a sua inteligibilidade, a sua mensagem, e não o rigorismo artificial da perfeição acadêmica. Mesmo em usa descrição da realidade enquanto temas típicos do imaginário romântico, como paisagens e cenas campestres, não há espaço para suavizações e bucolismos. Se na primeira obra sobre o tema dos bandoleiros, Bandidos assaltando uma diligencia (GW 152) de 1770, há a possibilidade de idealização, na segunda, $O$ assalto à diligencia $(\mathrm{GW} 251)$ de 1787, já não há idealização nenhuma, os bandidos são cruéis e implacáveis e não guardam semelhança nenhuma com os nobres anti-heróis românticos de Os Bandoleiros de Schiller publicado em 1781.

Nenhum vestígio de uma visão romântica dos fora da lei: são assassinos sem piedade. A violência se mostra aqui em estado puro, indiferente a qualquer norma social (TODOROV, 2014, p. 45).

Com a revolução particular em sua pintura, realizada por Goya no último quarto do século XVIII, inicia-se uma ruptura com as tradições da pintura europeia que tinham uma perenidade de aproximadamente quatrocentos anos e que, por sua vez, vinham herdando diversas de suas regras e hábitos dos tratados medievais de iconologia. A fundamentação divina recua do mundo tanto nas artes quanto na política. Naquelas, o artista não é mais um mero imitador da beleza divina colocada no mundo, ele então cria mundo, usurpa a função do criador divino e não se refere a sua obra mais exclusivamente através do compromisso agradável da beleza. Nesta, o direito divino de governar rola pelas escadas do cadafalso junto com a cabeça dos reis que Deus elegeu, mas não foi capaz de proteger. Surge um mundo novo: livre, luminoso, monstruoso, assustador e vazio. É o mundo da genialidade da obra de Goya e de sua denúncia e crítica social, um mundo no qual o real não é o verdadeiro. Suas gravuras estão repletas de seres grotescos, figuras monstruosas, de rostos distorcidos ou mascarados, em um processo de desnudamento involuntário, pois a mesma máscara que esconde o rosto é capaz de desnudar uma interioridade de outra forma imperceptível. Explicita-se, assim, a dualidade entre interior e exterior, entre essência e aparência, entre uma exterioridade fingida aos demais e a si mesmo e uma interioridade secreta e inconfessável que apenas a máscara, que deveria escondê-la, é capaz de revelar (TODOROV, 2014, p. 61).

Nesse momento de transição entre o Antigo Regime e a República, entre o Barroco e o Iluminismo, com a relativização dos papéis sociais ocasionada 
pela derrocada da ordem social fundamentada na transcendência ontológica, parece se acentuar a ideia barroca do papel social como máscara e da vida como um teatro no qual cada um interpreta, malogradamente, o papel que lhe cabe. Uma versão da máscara na obra de Goya é a caricatura, através da qual os traços mais grotescos que o pintor está destacando aparecem exageradamente e sem possibilidade de disfarce. Ele mesmo um mascarado, pintor dos nobres com ideias republicanas, percebe, nos demais sujeitos e na sociedade como um todo, as máscaras e o palco da hipocrisia, a expressão pública que esconde o abismo dos vícios privados.

O mundo é uma mascarada: rostos, trajes, vozes, tudo é fingido; todos querem aparentar o que não são, todos se enganam reciprocamente e ninguém se conhece (GOYA, 2005 apud TODOROV, 2014, p. 87).

Isso se relaciona diretamente àquela ruptura com a tradição mimética representativa que destacamos acima, pois, na medida em que conquista sua independência em relação a apresentação da realidade e de seu conjunto de belas aparências, o artista está livre para representar a verdade grotesca subjacente ao véu inefável e ilusório da beleza. A máscara rude cintila a verdade que vai disfarçada sob o rosto que não é mais do que máscara bela. Ilusão ambas, mas aquela mais verdadeira do que esta. $\mathrm{E}$ entre o rol das ilusões que Goya denuncia, na lista das máscaras que ele desmascara, estão as superstições populares que são fonte de medo e fundamento para a dominação ideológica do clero, que se erige como defensor do povo contra a ameaça das bruxas.

Eu já não temo as bruxas, nem os duendes, nem os fantasmas, nem os gigantes fanfarrões, nem os poltrões, nem os larápios, nem qualquer tipo de ser, não temo nada nem ninguém, exceto os humanos (GOYA, 1982 apud TODOROV, 2014, p. 63).

$\mathrm{E}$ isso explica a razão pela qual figuras sobrenaturais aparecem nas obras de Goya, bruxas, monstros, demônios, o próprio Diabo em forma de um bode gigante, como em El Aquelarre ou o Sabá das Bruxas (GW 660): não é o indicativo de um possível satanismo de um artista amargurado pela doença ou perturbado pela loucura e pelo desespero, mas o sinal de uma arguta mente esclarecida que tem, como é comum em seu tempo, a intenção de zombar das crendices populares, levadas adiante por uma massa inculta e supersticiosa. O grande opositor não aparece na obra de Goya como um acusador do Iluminismo, se não como o seu confirmador mefistofélico.

O que ocorre na arte de Goya, o que dá o seu tom mais assustador e sombrio é exatamente o fato de que ele não está tematizando um mundo alternativo, no qual habitam monstros e fadas, maravilhas e prodígios, mas evidenciando a monstruosidade e a prodigiosidade desse mesmo mundo comum e sem graça que habitamos cotidianamente. Não é o processo de levar o olhar até o reino do maravilhoso, mas o de trazer à luz o maravilhoso que estava apenas escondido do olhar. "O sobrenatural já não 
habita os campos ou as florestas, mas o interior de nossa mente e, portanto, é perfeitamente explicável" (TODOROV, 2014, p. 88). Assim que a transcendência divina se ausentou da fundamentação ontológica da ordem social deixou um mundo vazio no qual a monstruosidade agora está apta a se tornar imanente e, portanto, ainda mais monstruosa. Ela não está mais fora, em outro mundo, senão dentro de cada um de nós.

Assim, a arte de Goya, ao tematizar o monstruoso, serve a um duplo propósito, aparentemente antagônico, o de colocar em pauta a fragilidade das superstições e medos populares e de denunciar nesses terrores uma verdade inerente ao espírito humano. Os monstros não existem. Não fora de nós. Este é, então, o tema de seus caprichos, o monstruoso dentro do humano. Essa série de gravuras concentra toda a dualidade da obra de Goya e seu paradoxo, ao mesmo tempo explicitando a sátira de sua sociedade e revelando os aspectos sombrios do inconsciente de uma época que ecoam nas figuras representadas. De outro modo as gravuras não causariam escândalo, pois suas referências veladas não seriam passíveis de decodificação racional ou de provocar reações estéticas por associação.

E é justamente por essa interação entre interior e exterior, entre o que está escondido e o que se pretende mostrar, que é reconhecida a grandiosidade das gravuras de Goya. Porém, ao falarmos de Iluminismo, sem dúvida a gravura mais eloquente e conhecida é o Capricho $n^{\circ}$ 43, também conhecida pela frase que ostenta, caso único em sua série, El sueño de la razón produce monstruos. Todorov chama a atenção para a ambiguidade possível do termo sueño em espanhol, que pode tanto significar sono como sonho. No primeiro caso, corresponderia a dizer que, quando a racionalidade cochila, os monstros noturnos que representam a obscuridade do pensamento não esclarecido retornam para assombrar o mundo, insinuando a necessidade de uma racionalidade sempre vigilante, a fim de conter os impulsos demoníacos escondidos no interior dos homens. Mas o segundo caso, interpretação corroborada pelas aparições anteriores da palavra sueño na obra de Goya, é ainda mais grave, pois insinua que é no sonho, entendido então como devaneio, mas para nós entendido claramente como a realização inconsciente de um desejo inconfessado, que a racionalidade demonstra suas reais intenções. Se são os sonhos da razão que criam monstros, esses monstros não aparecem na ausência da razão, em seu descuido, mas estão dentro dela, são inerentes a ela, o cerne da racionalidade é a monstruosidade. É a presença da razão que gera monstros, não a sua ausência sonolenta. 
Figura 4 - Capricho no 43, El sueño de la razón produce monstruos

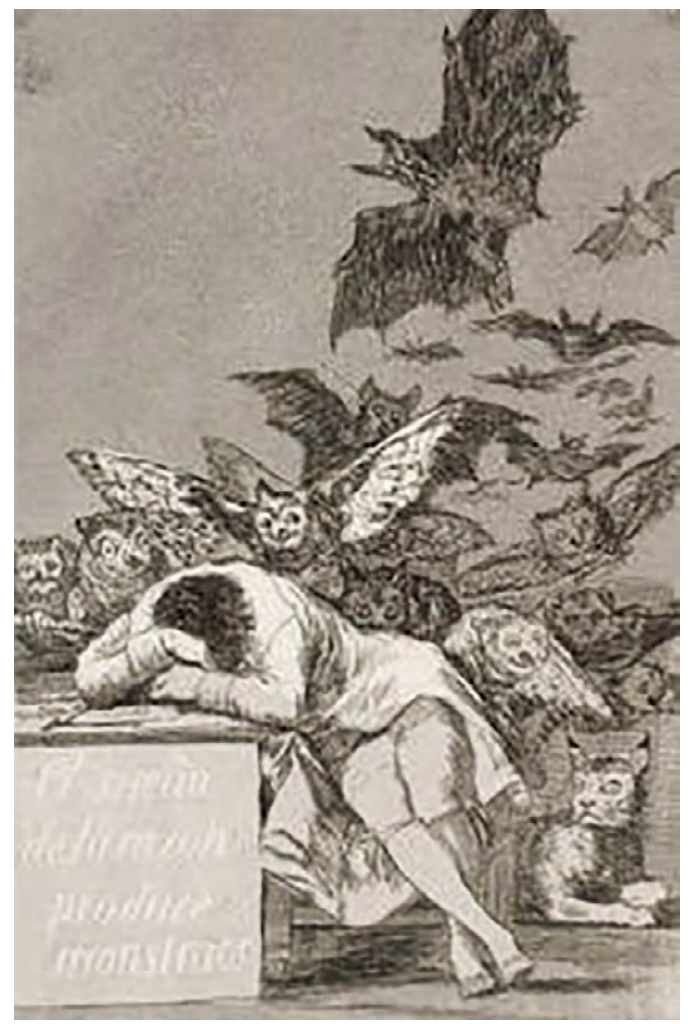

Fonte: Goya (1799).

A ideia de uma imaginação desregrada e errante, muito em voga no século XVIII, corresponde à incapacidade da razão de manter-se em seus limites, de conter e suportar-se, vindo a cair na loucura, no devaneio racional, correspondendo, na filosofia da época, à visão kantiana, na qual a fantasia e o impossível, e com eles o que for assustador e feio, residiriam fora dos limites da razão, de maneira a demonstrar a monstruosidade potencial de uma racionalidade limitadora, porque desmedida (TIBURI, 2001, p. 55). Nessa gravura, são retratados os perigos potenciais da racionalidade quando esta descamba para o seu lado mais negro, de angústia, medo, abismo e terror. A cena mostra um homem deitado sobre os braços cruzados, que se apoiam sobre uma mesa de trabalho, na qual também jazem livros fechados e objetos de escrita displicentemente abandonados. "La fantasía abandonada de la razón produce monstruos imposibles; unida con ella es madre de las artes y origen de sus marabillas" (GOYA, 1988 apud NORDSTRÖM, 1989, p. 141). Tal sonho da razão é povoado de diversos animais noturnos e sombrios, morcegos, corujas, gatos e até um lince. As corujas e os mochos, além de serem animais noturnos e compartilharem hábitos com os morcegos, também são a representação da erudição e da sabedoria, de acordo com a iconografia clássica da deusa Atena, deusa de artes e ofícios, das ciências e do conhecimento. Notamos que uma das corujas, bem à esquerda, transporta uma pena e parece oferecê-la ao artista, como que a insinuar que o trabalho seria uma alternativa para sair de seu sofrimento e agonia. As opções entre as quais se debate o sonhador, entre as feras da imaginação desenfreada e a razão, transpostas na gravura como a sombra na qual estão os morcegos maiores do fundo em contraste com a claridade e a definição de traços das corujas e do lince, em um plano mais próximo, representam, em verdade, a diferença entre a melancolia paralisante e a criação artística. $\mathrm{O}$ gato 
negro, juntamente com os morcegos, personifica a obscuridade, enquanto o lince é, tradicionalmente, a representação da fantasia, da imaginação, e está ali para apoiar o sonhador, já que é reconhecida a sua fama de ter visão penetrante, sendo capaz de enxergar perfeitamente, ainda que na mais completa obscuridade.

A bravura mostra um homem adormecido
sobre sua escrivaninha, cercado por aves
noturnas, morcegos e mochos, assim como
por um gato enorme, na época símbolos
familiares da estupidez e da ignorância, ou
mesmo do próprio diabo. [...] Na gravura, os
animais noturnos são acompanhados de um
lince, animal famoso pela acuidade de sua
visão: a cegueira e a visão aguda coexistem
sempre (TODOROV, 2014, p. 82 ).

Isso demonstra uma certa clareza, na intuição de Goya, de que os elementos obscuros da alma humana não podem ser eliminados pela razão, se não diligentemente controlados por ela em um processo que não pode se contentar em ser apenas crítico, mas igualmente autocrítico, ou seja, tudo o que o desenvolvimento instrumental da razão iluminista não foi.

O projeto já não é destruir as superstições e as fantasias, mas compreendê-las e, consequentemente, domesticá-las; quando ele o consegue, essas visões, longe de causar medo, fazem rir (TODOROV, 2014, p. 81).

Vemos então uma proposta de superação da dicotomia entre razão e fantasia que raramente acontece no pensamento ocidental. Em vez de sugerir que a razão preceda o banimento dos elementos irracionais que lhe escapam e transcendem, Goya propõe uma integração desses dois aspectos, em direção a uma completude capaz de sanar a Enfermidade da razão (GW 623 e GW 551 - capricho no 50), que é o título de um desenho preparatório a esta gravura tão célebre. $\mathrm{Na}$ descrição destes estudos, há uma interpretação ligeiramente diferente ainda que complementar dos elementos obscuros que assombram a cena e que aparecem também em outras peças importantes, como a alegoria chamada $A$ Verdade, o Tempo e a História (GW 696), que mostra estes três personagens atacados por uma revoada de animais fantasmagóricos e protegidos apenas por uma onda de luz esclarecida e racional.

\section{Considerações finais}

Os argumentos que se teceram até aqui não tiveram a mínima intenção de serem exaustivos, de maneira que diversas outras abordagens da obra de Goya poderiam complementar estas reflexões, levando-as para outros espaços e outras obras. Nossa intenção foi demonstrar o quanto se pode perceber as características de um mundo em crise e em pleno processo de transformação a partir da obra de um artista, chamando atenção para a ambiguidade de sua própria atividade artístico-intelectual, no caso os retratos de corte, integrada à lógica de um sistema político e social em desaparecimento, nos quais o autor consegue exercer uma crítica sutil através, por um lado, da obediência formal e, por outro lado, da obra crítica social. No 
caso, em suas gravuras, identificam-se elementos negativos dentro do próprio processo de transformação social que o autor endossa. É esta profundidade de pensamento, esta impossibilidade de classificar tanto a obra de Goya como um todo quanto suas produções particulares em um esquema simplista que poderia ser de oposição entre iluminista ou anti-iluminista, conformista ou rebelde, que justifica a genialidade que a tradição lhe imuta e que tanto nos instigou aqui a tecer tais reflexões e realizar tais análises.

Uma possível continuidade dessa argumentação da presença do pensamento iluminista na obra de Goya poderia estar sobre suas demais gravuras, com suas imagens de bruxas volantes e religiosos simiescos, bem como a crítica a este iluminismo poderia ser vista com clareza nas gravuras dos corpos desmembrados pelos soldados napoleônicos, que foram libertar o povo espanhol através da violência, mas isso será escopo de outras produções.

\section{Les ambiguïtés des Lumières dans certaines œuvres de Francisco de Goya: lecture des images}

\section{Résumé}

Il s'agit d'identifier les ambiguïtés de la pensée de Goya et de travailler à travers l'analyse de certains de ses portraits - Carlos IV (1789), Reine María Luisa con tontillo (1789) et La Familia de Carlos IV (1800) - et le plus célèbre de ses gravures - Capri- cho \# 43, El sueño de la razón produce monstruos (1799). À de telles ambiguités, nous raconterons les plus importantes caractéristiques de la période historique dans laquelle l'artiste a vécu, rempli de transformations sociales et culturelles, afin de, grâce à une analyse réflexive des images, comprendre à quel point ce que Goya faisait un innovation en peinture à la fois qu'il était pleinement intégré dans la société que ses attachements intellectuels critiquaient et ont aidée a transformer. Enfin, nous suivrons la critique des lumières naissantes qui est déjà apparue dans ses gravures, en particulier celle déjà mentionnée.

Mots-clé: Goya. Lecture d'image. Les Lumières.

\section{Referências}

ABAGNANO, Nicola. Iluminismo. In:

Dicionário de Filosofia. São Paulo: Mestre Jou, 1981. p. 509-511.

ADORNO, Theodor W.; HORKHEIMER, Max. O Conceito de Esclarecimento. In: . Dialética do Esclarecimento: fragmentos filosóficos. Rio de Janeiro: Jorge Zahar, 2006. p. 17-46.

EISENMAN, Stephen F. Historia crítica del arte del siglo XIX. Madrid: Ibérica, 2001.

ELIAS, Norbert. A sociedade de corte: investigação sobre a sociologia da realeza e da aristocracia de corte. Tradução de Pedro Süssekind. Rio de Janeiro: Jorge Zahar, 2001.

GOMBRICH, Ernst H. A História da Arte. Rio de Janeiro: LTC, 2013.

GOYA, Francisco de. Carlos IV. (1789). Óleo sobre tela, $280 \mathrm{~cm}$ x $336 \mathrm{~cm}$. Museo del Prado. Disponível em: <https://upload.wikimedia. org/wikipedia/commons/2/2e/Carlos_IV_de_ rojo.jpg>. Acesso em: 02 jul. 2017. 
. El sueño de la razón produce monstruos, grabado no 43 de los Caprichos (17971799). (1799) Gravura em águaforte e outras técnicas de incisão sobre papel prensado. 213 mm x $151 \mathrm{~mm}$ (huella) / $306 \mathrm{~mm}$ x $201 \mathrm{~mm}$ (papel). Museo del Prado Disponível em: <https://es.wikipedia.org/wiki/El_sue\%C3\%B1o_ de_la_raz\%C3\%B3n_produce_monstruos\#/ media/File:Francisco_Jos\%C3\%A9_de_ Goya_y_Lucientes_-_The_sleep_of_reason_ produces_monsters_(No._43),_from_Los_Caprichos_-_Google_Art_Project.jpg $>$. Acesso em: 03 maio 2017.

. La familia de Carlos IV. (1800). Óleo sobre tela, $205 \mathrm{~cm}$ x $132 \mathrm{~cm}$. Museo del Prado. Disponível em: <https:/upload.wikimedia. org/wikipedia/commons/e/ed/Maria_Luisa_de_Parma_con_tontillo.jpg $>$. Acesso em: 02 jul. 2017.

La reina María Luisa con tontillo. (1789). Óleo sobre tela, $205 \mathrm{~cm} \mathrm{x} 132 \mathrm{~cm}$. Museo del Prado. Disponível em: <https:// upload.wikimedia.org/wikipedia/commons/e/ ed/Maria_Luisa_de_Parma_con_tontillo. jpg>. Acesso em: 02 jul. 2017.

KANT, Immanuel. Resposta à pergunta: “O que é Esclarecimento [Aufklärung]?". 1783. Disponível em: <https://www.ufsm.br/ gpforma/2senafe/PDF/b47.pdf>. Acesso em: 13 abr. 2017.

NORDSTRÖM, Folke. Goya, Saturno y Melancolía: consideraciones sobre el arte de Goya. Madrid: Visor, 1989.

SÁNCHEZ-BLANCO, Francisco. La Ilustración goyesca: la cultura en España durante el reinado de Carlos IV (1788-1808). Madrid: Editora 85, 2007. (Colección Cuadernos y Debates, v. 178).

TIBURI, Márcia. O Feio e o Mal: aquém dos juízos éticos e estéticos. Filosofia Unisinos, São Leopoldo, v. II, n. 2, p. 55-74, jan./jun. 2001.

TODOROV, Tzvetan. Goya à sombra das luzes. São Paulo: Companhia das Letras, 2014.
TORRES, Pedro Ruiz. Reformismo e Ilustración. In: FONTANA, Josep; VILLARES, Ramón (Dir.). História de España. Espanha: Crítica/Marcial Pons, 2008. p. 527-626. 